\title{
Second Crop of Corn Cultivation and Soybean Agricultural Evaluation of Characters and Their Relationships
}

\author{
Mustafa Okant (Corresponding author) \\ Harran University, Faculty of Agriculture, Department of Agronomy, Sanliurfa, Turkey \\ E-mail: mokant63@yahoo.com \\ Turan Saglamtimur \\ Cukurova University, Faculty of Agriculture, Department of Agronomy, Adana, Turkey \\ E-mail: saglamtimur@cu.edu.tr
}

\begin{abstract}
This research was carried out in the summer season of 1990-1991 vegetation in order to determine the most suitable sowing rates of corn and soybean to be grown in Çukurova ecological conditions. In the trial; LG 55 medium late hybrid corn and SA 88 soybean were used as materials. Sowing ratios subject to the experiment are 1 Corn $(10,15,20 \mathrm{~cm})+1$ Soybean $(2.5$ and $5.0 \mathrm{~cm})$ and 2 Corn $(10,15,20 \mathrm{~cm})+2$ Soybean together with pure corn $(70 \mathrm{~cm} \times 20 \mathrm{~cm})$ and soybean parcels $(35 \mathrm{~cm} \times 5.0 \mathrm{~cm}) .(2.5$ and $5.0 \mathrm{~cm})$ mixture threads were included. Accordingly, each block consists of 14 plots and four repetitive random blocks were run according to the trial pattern. In the co-cultivated corn, there is a significant and positive relationship between plant height, first cob height and crude protein yield, and a negative significant relationship between peak tassel emergence and the number of days of ripening.

In the co-cultivated soybean significant and positive relationship between the number of branches in the soybean and the number of beans, important and positive relationship between grain yield and crude protein yield and there was a significant and negative relationship between $50 \%$ of the number of days of flowering of the same character. Findings obtained showed that in co-cultivation system studies, plant height in corn, the height of the first cob, number of branches in soybean, number of broad beans, and number of seeds in broad beans have vegetative features that should be emphasized.
\end{abstract}

Keywords: Corn, soybean, co-cultivation, grain yield, correlation coefficients

DOI: $10.7176 / \mathrm{JSTR} / 6-04-09$

\section{Birlikte Yetiştirmenin İkinci Ürün Mısır ve Soyada Tarımsal Karakterler ve İlişkileri Yönünden Değerlendirilmesi}

\begin{abstract}
Özet
$\mathrm{Bu}$ araştırmada; Çukurova ekolojik koşullarında yetiştirilecek mısır ve soyanın en uygun ekim oranlarının belirlenmesi amacıyla 1990-1991 vejetasyonun yaz sezonunda yürütülmüştür. Denemede; LG 55 orta geççi hibrid mısır çeşiti ile SA 88 soya çeşiti idi materyal olarak kullanılmıştır. Denemeye konu olan ekim oranlar1 saf Misır $(70 \mathrm{~cm} \times 20 \mathrm{~cm})$ ve Soya parselleri $(35 \mathrm{cmx} 5.0 \mathrm{~cm})$ ile birlikte, $1 \mathrm{M} 1 \mathrm{sir}$ $(10,15,20 \mathrm{~cm})+1$ Soya $(2.5$ ve $5.0 \mathrm{~cm})$ ve 2 Misır $(10,15,20 \mathrm{~cm})+2$ Soya $(2.5 \mathrm{ve} 5.0 \mathrm{~cm})$ karışım konuları yer almıştır. Buna çalışmada her bir blok 14 parselden oluşmuş ve dört tekrarlamalı tesadüf blokları deneme desenine göre yürütülmüştür. Karışıma giren mısırda bitki boyu, ilk koçan yüksekliği ve ham protein verimi arasında önemli ve olumlu, tepe püskülü çıkışı ve olgunlaşma gün sayısı arasında ise önemli ve olumsuz ilişki söz konusudur.

Karışıma giren soyada dal sayısı ile bakla sayısı, baklada tohum sayısı arasında önemli ve olumlu ilişki, bitki başına tohum veriminin bin tane ağırlığı, tane verimi ve ham protein verimi arasında önemli ve olumlu ilişki, aynı karakterin \%50 çiçeklenme gün sayısı arasında ise önemli ve olumsuz ilişki saptanmıştır. Elde edilen bulgular; birlikte yetiştirme sistemi çalışmalarında mısırda bitki boyu, ilk koçan yüksekliği, soyada ise dal sayısı, bakla sayısı, baklada tohum sayısının üzerinde durulması gereken bitkisel özellikler olduğunu göstermektedir.
\end{abstract}

Anahtar Kelimeler: Mısır, soya, birlikte yetiştirme, tane verimi, karakterler arası ilişkiler 


\section{Giriş}

Dünyada ve ülkemizde özellikle son yarım yüzyılda nüfusta meydana gelen hızlı artışa paralel olarak gıda maddeleri ihtiyacı da büyük artış göstermiştir. Yeni tarım alanları oluşturma olanağı çok az olduğu için ihtiyacı karşılayacak bitkisel üretim, mevcut koşullardan en iyi şekilde yararlanmayı sağlayacak çeşitli üretim yöntemleri ile sağlanmaktadır. Bu yöntemlerden birisi de, bugün için daha çok küçük işletmelere uygun görülen karışık (birlikte) ekim sistemidir.

Bitkisel üretimi artırmada izlenebilecek yollardan biride, ekolojik şartlara bağlı kalarak yılda birden fazla ürün almaktır. Çoklu üretimden başka birlikte yetiştirme (karışım ekim) ile de mümkün olmaktadır.

Birlikte üretim; özellikle toprak kaynakları sınırlı küçük çiftçiler arasında potansiyel yöntem olarak önerilmektedir (Singh ve Awasthi 1984). Bu sistem en az iki bitkinin aynı arazide aynı anda yetiştirilmesi anlamına gelmektedir (Tansı, 1987; Boz, 2006). Toprak kaynakları sınırlı küçük işletme sahipleri bu ülkelerde mevcut kaynakları daha iyi kullanmakta en az iki farklı bitkiyi birlikte yetiştirerek risk unsurunu azaltmakta, toprağın verimliliğini koruduğu, erozyonu önleyip daha iyi yabancı ot kontrolüne imkan tanıdığı, hastalık ve zararlı epidemisini azalttığını ve özellikle de aile iş gücünün daha verimli kullanılmasına imkan sağlayarak karlılığı artırdığınından dolayı bu sistemi tercih etmektedirler (Tansı, 1987).

Birlikte yetiştirmede en uygun karışımlar buğdaygil+baklagil şeklindeki karışımlardır (Bryon ve Peprah, 1988; Shah ve ark., 1991).

Ülkemiz'de üretilen misırın \%35'i insan beslenmesinde, \%30'u hayvan beslenmesinde, \%20'si yem sanayide ve \%15'lik kısmı ise diğer alanlarda kullanılmaktadır (Gençtan ve ark., 1995). Araştırmamızda kullandığımız diğer bitki olan soyanın tohumları ise, \%18-26 yă̆ ve \%40 protein içermektedir. Tohumdaki proteinde bulunan lycine hayvan beslenmesinde oldukça önemli bir yere sahiptir (Kolsarıcı ve ark., 2006).

Çalışmanın amacı; tane amacıyla ikinci ürün olarak birlikte yetiştirilecek mısır+soya bitkilerinin en uygun ekim sistemi ile bitki sıklıklarının saf ve karışımda bazı tarımsal karakterlere etkilerini belirlemektir

\section{Materyal Ve Yöntem}

Araştırma; Adana ili ekolojik şartlarında yürütülmüş ve Haziran Ayı’nın ilk haftasında tesadüf blokları deneme deseni profiline göre 4 tekrarlamalı olacak şekilde kurulmuş, mısır LG-55 tek melezi, SA 88 soya çeşidi materyal olarak kullanılmıştır. Yalın ve farklı karışım oranları ele alınmıştır. Buna göre her bir blok 14 parselden oluşmuştur. Denemede kullanılan karışım oranları. saf Misır $(70 \mathrm{~cm}$ x20cm) ve Soya parselleri $(35 \mathrm{cmx} 5.0 \mathrm{~cm})$ ile birlikte, 1 Misir $(10,15,20 \mathrm{~cm})+1$ Soya $(2.5 \mathrm{ve} 5.0 \mathrm{~cm})$ ve 2 Misır $(10,15,20$ $\mathrm{cm})+2$ Soya $(2.5 \mathrm{ve} 5.0 \mathrm{~cm})$ şeklinde oluşturulmuştur.

\subsection{Deneme alanının bazı toprak ve iklim özellikleri}

Çizelge 1'de izlendiği gibi deneme alanının toprak tekstürü çoğunlukla tınlı yapıdadır. Organik madde içeriği (\% 0.73-1.91), tuz içeriği (0.13-0.25) olup, alt katmanlara doğru azalmaktadır. Tüm profilde ise kireç miktarı yüksek tespit edilmiştir (Özberk ve ark., 1974).

Adana ilinde, denemenin yürütüldüğü aylara ait bazı iklim verileri Çizelge 2'de verilmiştir. Deneme yıllarındaki ortalama sicaklık değerleri, uzun yıllar ortalamasından daha yüksek bulunmuştur. Denemenin yürütüldüğü 1990 yılında dolu yağışı saptanmış olup en yüksek yağış 63.6 mm ile Haziran ayında, en düşük yağış her iki yılda da Temmuz ayında gözlenmiş ve beş aylık dönemde 1990 deneme yılında toplam $115.50 \mathrm{~mm}, 1991$ deneme yılında ise $57.7 \mathrm{~mm}$ yağış düşmüştür. Denemenin yürütüldüğü yıllarında oransal nem değerleri, bütün aylarda uzun yıllar ortalamasından düşük çıkmıştır (Anonim, 1990-1991).

Ekim; Haziran ayının ilk haftasında markörle açılan sıralara saf Mısır (7150 bitki/da) ve saf Soya parselleri (28575 bitki/da) ile birlikte yetiştirmede, 1Misır (3571-4762-7150 bitki/da)+1Soya (2857514286 bitki/da) ve 2Misır (3571-4762-7150 bitki/da)+2Soya (28575-14286 bitki/da) şeklinde elle ekim yapılmıştır. Ekimde parsel alanı $6 \mathrm{~m}$ x $5.6 \mathrm{~m}=33.6 \mathrm{~m}^{2}$ Deneme yaz yetiştirme sezonunda yürütülmüştür. Ekimle beraber taban gübresi olarak saf ve birlikte ekilen misıra $10 \mathrm{~kg} / \mathrm{da}$, azot ve $10 \mathrm{~kg} / \mathrm{da}$ fosfor gübresi, bitkiler 50-60 cm boylandığında $6 \mathrm{~kg} / \mathrm{da}$ amonyum nitrat toprağa elle karıştırılarak verilmiştir. Saf ekilen soya bitkisine ise $5 \mathrm{~kg} / \mathrm{da}$ azot ve fosfor ekimden önce uygulanmıştır. 
Çizelge 1. Araştırma alanının bazı toprak özellikleri (Özberk ve ark. 1974)

\begin{tabular}{l|l|l|l|l|l|l|l}
\hline Horizon & $\begin{array}{l}\text { Derinlik } \\
(\mathrm{cm})\end{array}$ & Tekstür & Kireç & $\begin{array}{l}\text { Ec 25 } 5^{0} \mathrm{C} \\
\mathrm{mmhos} / \mathrm{cm} \\
\mathrm{kg} / \mathrm{da}\end{array}$ & $\begin{array}{l}\text { Yararl1 } \\
\mathrm{P}_{2} \mathrm{O}_{5}\end{array}$ & $\begin{array}{l}\text { Organik } \\
\text { madde } \\
(\%)\end{array}$ & $\begin{array}{l}\text { Geçirgenlik } \\
\mathrm{cm} / \mathrm{saat}\end{array}$ \\
\hline $\mathrm{Ap}$ & $0-6$ & Tin & 5148 & 0.25 & 1.54 & 1.60 & 1.45 \\
\hline $\mathrm{A} 12$ & $6-21$ & Tin & 38.80 & 0.23 & --- & 1.91 & 2.46 \\
\hline $\mathrm{A} 13$ & $21-47$ & Silt-Tin & 37.22 & 0.14 & --- & 1.47 & 2.32 \\
\hline $\mathrm{C}$ & $47-74$ & Tin & 53.46 & 0.13 & --- & 0.73 & 2.03 \\
\hline
\end{tabular}

Çizelge 2. Adana iline ait 1990-91 ve uzun ylllar iklim verileri (Anonim, 1990-1991)

\begin{tabular}{|c|c|c|c|c|}
\hline AYLAR & Yillar & $\begin{array}{l}\text { Ort. sic. } \\
\left({ }^{0} \mathrm{C}\right)\end{array}$ & $\begin{array}{l}\text { Ort. nispi nem } \\
\qquad \%)\end{array}$ & $\begin{array}{l}\text { Yağıș toplamı } \\
\left(\mathrm{kg} / \mathrm{m}^{2}\right)\end{array}$ \\
\hline \multirow{2}{*}{ Haziran } & $\begin{array}{l}1990 \\
1991 \\
\end{array}$ & $\begin{array}{l}25.4 \\
25.7 \\
\end{array}$ & $\begin{array}{l}57.8 \\
65.5 \\
\end{array}$ & $\begin{array}{l}63.6 \\
2.9 \\
\end{array}$ \\
\hline & Uzun Y1l Ort. & 25.1 & 66.0 & 20.7 \\
\hline \multirow{2}{*}{ Temmuz } & $\begin{array}{l}1990 \\
1991 \\
\end{array}$ & $\begin{array}{l}28.1 \\
27.9\end{array}$ & $\begin{array}{l}67.7 \\
66.3\end{array}$ & $\begin{array}{l}0.0 \\
2.1\end{array}$ \\
\hline & Uzun Y1l Ort. & 28.1 & 67.7 & 0.0 \\
\hline \multirow{2}{*}{ Ağustos } & $\begin{array}{l}1990 \\
1991 \\
\end{array}$ & $\begin{array}{l}28.4 \\
28.5\end{array}$ & $\begin{array}{l}64.0 \\
66.9 \\
\end{array}$ & $\begin{array}{l}0.2 \\
3.1 \\
\end{array}$ \\
\hline & Uzun Y1l Ort. & 28.0 & 67.0 & 8.0 \\
\hline \multirow{2}{*}{ Eylül } & $\begin{array}{l}1990 \\
1991 \\
\end{array}$ & $\begin{array}{l}25.9 \\
26.5 \\
\end{array}$ & $\begin{array}{l}57.7 \\
59.7 \\
\end{array}$ & $\begin{array}{l}16.3 \\
10.7 \\
\end{array}$ \\
\hline & Uzun Yil Ort. & 25.3 & 62.0 & 17.0 \\
\hline \multirow{2}{*}{ Ekim } & $\begin{array}{l}1990 \\
1991\end{array}$ & $\begin{array}{l}23.0 \\
22.7\end{array}$ & $\begin{array}{l}46.4 \\
59.7 \\
\end{array}$ & $\begin{array}{l}35.4 \\
38.9 \\
\end{array}$ \\
\hline & Uzun Y1l Ort. & 20.9 & 60.0 & 39.9 \\
\hline Toplam & $\begin{array}{c}1990 \\
1991 \\
\text { Uzun Yil Ort. }\end{array}$ & & & $\begin{array}{l}115.5 \\
57.7 \\
84.7\end{array}$ \\
\hline
\end{tabular}

Hasat; mısır bitkisinde kavuzlar tamamen kuruyup taneler sertleştiğinde, soya bitkisinde ise baklalar kuruyup kahverengiye dönüştüğünde blok başlarına tesadüf eden parsellerde $5 \mathrm{~m} \times 4.2 \mathrm{~m}=21.0 \mathrm{~m}^{2}$ diğer parsellerde $5 \mathrm{~m} \times 5.6 \mathrm{~m}=28.0 \mathrm{~m}^{2}$ olarak yapılmıştır.

Denemede; mısır bitkisinde bitki boyu (cm), bitki çapı $(\mathrm{mm})$, ilk koçan yüksekliği $(\mathrm{cm})$, koçan sayısı (adet/bitki), koçan boyu ( $\mathrm{cm})$, koçan çap1 $(\mathrm{mm})$, koçan ağırlığ $1(\mathrm{~g})$, bin tane ağırlığı $(\mathrm{g})$, tepe püskülü çıkış süresi (gün), olgunlaşma gün sayısı (gün), tane verimi $(\mathrm{kg} / \mathrm{da}$ ), ham protein verimi $(\mathrm{kg} / \mathrm{da})$. Soyada bitki boyu (cm), ilk bakla yüksekliği $(\mathrm{cm})$, dal sayısı (adet/bitki), bakla sayısı (adet/bitki), baklada tohum sayısı (adet/bitki), bitki başına tane verimi (g/bitki), bin tane ağıllı̆ı $(\mathrm{g})$, tane verimi $(\mathrm{kg} / \mathrm{da}), \% 50$ çiçeklenme gün sayısı (gün), olgunlaşma gün sayısı (gün), ham protein verimi $(\mathrm{kg} / \mathrm{da})$ incelenmiş, Ege istatistik paket programı kullanılarak varyans analizleri yapılmıs, ortalamalar ise lsd (\%5) çoklu karşılaştırma testiyle belirlenmiş̧ir.

\section{Bulgular, Tartışma ve Sonuç}

Çukurova koşullarında 1990 ve 19912016 yaz yetiştirme döneminde yetiştirilen 14 farklı ekim sistemlerinde incelenen bitkisel özelliklere ilişkin iki yıllık ortalama veriler ve E.G.F (En küçük Güvenilir Fark) testine göre oluşan gruplar Çizelge 3, 4, 5 ve 6'da verilmiştir. Çizelge 3 ve 4'den mısır bitkisinde en yüksek bitki boyu saf Misır $70 \mathrm{~cm} \times 20 \mathrm{~cm}, 1 \mathrm{M}+1 \mathrm{~S} 20 \mathrm{~cm} \times 2.5 \mathrm{~cm}, 2 \mathrm{M}+2 \mathrm{~S} 20 \mathrm{~cm} \times 2.5 \mathrm{~cm}$ ve $2 \mathrm{M}+2 \mathrm{~S} 15 \mathrm{~cm} \times 2.5 \mathrm{~cm}$ uygulamalarından, en düşük değer ise $2 \mathrm{M}+2 \mathrm{~S} 10 \mathrm{~cm} \times 2.5 \mathrm{~cm}$ ekim sisteminden ölçülmüsşür. En yüksek değerin saf mısırdan elde edilmesi soyanın mısır bitkisini etkileyecek kadar rekabet oluşturmaması ile açıklanabilir (Putnam ve ark. 1985). En yüksek bitki çapı saf Mısır $70 \mathrm{~cm} \times 20 \mathrm{~cm}$, en düşük değeri ise $2 \mathrm{M}+2 \mathrm{~S} 10 \mathrm{~cm} \times 2.5 \mathrm{~cm}$ ve $2 \mathrm{M}+2 \mathrm{~S} 10 \mathrm{~cm} \times 5.0 \mathrm{~cm}$ uygulamalarından, en yüksek ilk koçan değeri saf Misır $70 \mathrm{cmx} 20 \mathrm{~cm}, 1 \mathrm{M}+1 \mathrm{~S} 20 \mathrm{cmx} 2.5 \mathrm{~cm}, 1 \mathrm{M}+1 \mathrm{~S} 20 \mathrm{~cm} \times 5.0 \mathrm{~cm}, 2 \mathrm{M}+2 \mathrm{~S}$ $20 \mathrm{~cm} \times 2.5 \mathrm{~cm}$ ve $2 \mathrm{M}+2 \mathrm{~S} 15 \mathrm{~cm} \times 5.0 \mathrm{~cm}$ parsellerinde, en düşüğü $2 \mathrm{M}+2 \mathrm{~S} 20 \mathrm{~cm} \times 2.5 \mathrm{~cm}$ parselinden, koçan sayısının en yüksek değeri $1 \mathrm{M}+1 \mathrm{~S} 10 \mathrm{~cm} \times 5.0 \mathrm{~cm}$, en düşüğü ise $2 \mathrm{M}+2 \mathrm{~S} 15 \mathrm{~cm} \times 5.0 \mathrm{~cm}$ parselinden, en yüksek koçan boyu $1 \mathrm{M}+1 \mathrm{~S} 10 \mathrm{~cm} \times 2.5 \mathrm{~cm}$, en düşüğü $1 \mathrm{M}+1 \mathrm{~S} 20 \mathrm{~cm} \times 5.0 \mathrm{~cm}$ parselinden, en yüksek koçan 
çapı değeri $2 \mathrm{M}+2 \mathrm{~S} 10 \mathrm{~cm} \times 2.5 \mathrm{~cm}$, en düşüğü $1 \mathrm{M}+1 \mathrm{~S} 20 \mathrm{~cm} \times 2.5 \mathrm{~cm}, 1 \mathrm{M}+1 \mathrm{~S} 20 \mathrm{~cm} \times 5.0 \mathrm{~cm}$ ve $2 \mathrm{M}+2 \mathrm{~S}$ $15 \mathrm{~cm} \times 5.0 \mathrm{~cm}$ uygulamalarında saptanmıştır. Koçan ağırlığı karakterinin en yüksek değeri $1 \mathrm{M}+1 \mathrm{~S}$ $20 \mathrm{~cm} \times 2.5 \mathrm{~cm}$ ve $1 \mathrm{M}+1 \mathrm{~S} 20 \mathrm{~cm} \times 5.0 \mathrm{~cm}$ uygulamalarında en düşüğü ise $2 \mathrm{M}+2 \mathrm{~S} 10 \mathrm{~cm} \times 2.5 \mathrm{~cm}$ ve $2 \mathrm{M}+2 \mathrm{~S}$ $10 \mathrm{~cm} \times 5.0 \mathrm{~cm}$ 'den bin tane ağıllı̆̆ının en yüksek değeri saf Misır $70 \mathrm{cmx} 20 \mathrm{~cm}$ 'dan en düğü $1 \mathrm{M}+1 \mathrm{~S}$ $15 \mathrm{~cm} \times 5.0 \mathrm{~cm}$ ekim sisteminde, en yüksek tepe püskülü çıkış süresi $2 \mathrm{M}+2 \mathrm{~S} 10 \mathrm{~cm} \times 5.0 \mathrm{~cm}$ 'de en düşüğğ Saf Mısır 70cmx 20cm uygulamasında, olgunlaşma gün sayısının en yüksek değeri $1 \mathrm{M}+1 \mathrm{~S} 10 \mathrm{cmx} 5.0 \mathrm{~cm}$ den en düşüğü ise $1 \mathrm{M}+1 \mathrm{~S} 20 \mathrm{~cm} \times 5.0 \mathrm{~cm}$ 'deki ekim sisteminden, tane veriminin ekim sistemlerinde en yüksek değer $1 \mathrm{M}+1 \mathrm{~S} 20 \mathrm{~cm} \times 5.0 \mathrm{~cm}$ 'den, en düşük değer $2 \mathrm{M}+2 \mathrm{~S} 10 \mathrm{~cm} \times 2.5 \mathrm{~cm}$ 'den alınmıştır. Ham protein verimimde en yüksek $1 \mathrm{M}+1 \mathrm{~S} 20 \mathrm{~cm} \times 5.0 \mathrm{~cm}$, en düşük $2 \mathrm{M}+2 \mathrm{~S} 15 \mathrm{~cm} \times 5.0 \mathrm{~cm}$ uygulamalarında tespit edilmiştir.

Çizelge 5 incelendiğinde soya bitkisinde en yüksek bitki boyu $2 \mathrm{M}+2 \mathrm{~S} 15 \mathrm{~cm} \times 2.5 \mathrm{~cm}$ 'da en düşük değerin ise saf Soya $35 \mathrm{~cm} \times 5.0 \mathrm{~cm}, 1 \mathrm{M}+1 \mathrm{~S} 15 \mathrm{~cm} \times 5.0 \mathrm{~cm}, 1 \mathrm{M}+1 \mathrm{~S} 15 \mathrm{~cm} \times 2.5 \mathrm{~cm}$ ve $1 \mathrm{M}+1 \mathrm{~S} 20 \mathrm{~cm} \times 2.5 \mathrm{~cm}$ parsellerinden, ilk bakla yüksekliği değeri $1 \mathrm{M}+1 \mathrm{~S} 10 \mathrm{~cm} \times 2.5 \mathrm{~cm}$ 'den en düşük değere saf Soya $35 \mathrm{~cm} \times 5.0 \mathrm{~cm}$ 'de rastlanılmıştır. Dal sayısı karakterinde en yüksek veri $2 \mathrm{M}+2 \mathrm{~S} 15 \mathrm{~cm} \times 5.0 \mathrm{~cm}$ de en düşük veri ise $1 \mathrm{M}+1 \mathrm{~S} 10 \mathrm{~cm} \times 2.5 \mathrm{~cm}$ de alınmıştır. Bakla sayısı karakterinde en yüksek değer saf Soya $35 \mathrm{~cm} \times 5.0 \mathrm{~cm}$ 'den en düşük $1 \mathrm{M}+1 \mathrm{~S} 15 \mathrm{~cm} \times 5.0 \mathrm{~cm}$ 'de, baklada tohum sayıs 1 karakterinin en yükseği değeri saf Soya $35 \mathrm{~cm} \times 5.0 \mathrm{~cm}$, en düşüğü $1 \mathrm{M}+1 \mathrm{~S} 15 \mathrm{~cm} \times 5.0 \mathrm{~cm}$ den, bitki başına tane veriminin en yüksek değeri saf Soya $35 \mathrm{~cm} \times 5.0 \mathrm{c}$ 'de en düşüğü $1 \mathrm{M}+1 \mathrm{~S} 15 \mathrm{~cm} \times 5.0 \mathrm{~cm}$ 'de saptanmıştır (Çizelge 5). Bin tane ağırlığ 1 , tane verimi ve ham protein verimi karakterinin en yüksek değerleri saf Soya $35 \mathrm{~cm} \times 5.0 \mathrm{~cm}$ ekim sisteminde, en düşük değer rakamsal olarak sirasıyla $1 \mathrm{M}+1 \mathrm{~S} 15 \mathrm{~cm} \times 2.5 \mathrm{~cm}, 1 \mathrm{M}+1 \mathrm{~S} 20 \mathrm{~cm} \times 5.0 \mathrm{~cm}$ ve $1 \mathrm{M}+1 \mathrm{~S} 20 \mathrm{~cm} \times 5.0 \mathrm{~cm}$ sistemlerinden, $\% 50$ çiçeklenme gün sayısının en geç değeri $2 \mathrm{M}+2 \mathrm{~S}$ $10 \mathrm{~cm} \times 2.5 \mathrm{~cm}$ 'de en erken değeri saf Soya $35 \mathrm{~cm} \times 5.0 \mathrm{~cm}$ 'de saptanmış olup ışı̆̆ın, bitkide çiçeklenme gün sayısını kısaltabileceğini bildiren Eser (1986) ile bulgularımız uyumludur. Birlikte yetiştirme sistemlerinde bitki sıklığı artışı ile çiçeklenmenin geciktiği, bununda mısır bitkisinin karışıma giren soya bitkisi gölgelendirme etkisinden kaynaklanabileceğini bildiren Bilgen ve ark., (1991) ve Tansı (1987) ile uyum içerisindedir. Olgunlaşma gün sayısı karakterinde en uzun sürenin $1 \mathrm{M}+1 \mathrm{~S} 10 \mathrm{cmx} 2.5 \mathrm{~cm}$ ve $2 \mathrm{M}+2 \mathrm{~S}$ $15 \mathrm{~cm} \times 2.5 \mathrm{~cm}$ 'den, en kısa sürenin ise saf Soya $35 \mathrm{~cm} \times 5.0 \mathrm{~cm}$ ekim sisteminde saptanmıștır. Birlikte yetiştirme sistemleri uygulamalarının soya bitkisinde olgunlaşmayı geciktirdiği Çizelge 6'dan görülebilir. Bulgularım Tansı (1987)'nin bulguları ile uyuşmaktadır.

Çizelge 3. İkinci ürün tane mısırda birlikte yetiştirme uygulamaları ile bitki boyu, bitki çapı, ilk koçan yük, koçan sayısı, koçan boyu, koçan çapına ait iki yıl ortalama değerleri ve oluşan gruplar

\begin{tabular}{|c|c|c|c|c|c|c|}
\hline Uygulamalar & $\begin{array}{l}\begin{array}{l}\text { BB } \\
(\mathrm{cm})\end{array} \\
\end{array}$ & $\begin{array}{l}\mathrm{BÇ} \\
(\mathrm{mm})\end{array}$ & $\begin{array}{l}\mathrm{I} \mathrm{KY} \\
(\mathrm{cm})\end{array}$ & $\begin{array}{l}\mathrm{KS} \\
\text { (adet/bit.) }\end{array}$ & $\begin{array}{l}\begin{array}{l}\text { KB } \\
(\mathrm{cm})\end{array} \\
\end{array}$ & $\begin{array}{l}\begin{array}{l}\mathrm{KÇ} \\
(\mathrm{mm})\end{array} \\
\end{array}$ \\
\hline 1.Saf Misir $70 \mathrm{cmx} 20 \mathrm{~cm}$ & $249.21 \mathrm{a}$ & $22.58 \mathrm{a}$ & $98.16 \mathrm{a}$ & $1.06 \mathrm{de}$ & $19.10 \mathrm{def}$ & 44.64 c-e \\
\hline 2. $1 \mathrm{M}+1 \mathrm{~S} 20 \mathrm{~cm} \times 2.5 \mathrm{~cm}$ & $248.94 \mathrm{a}$ & $21.77 \mathrm{~b}$ & $98.10 \mathrm{a}$ & $1.06 \mathrm{de}$ & $18.06 \mathrm{gh}$ & $43.84 \mathrm{e}$ \\
\hline 3. $1 \mathrm{M}+1 \mathrm{~S} 20 \mathrm{~cm} \times 5.0 \mathrm{~cm}$ & $246.52 \mathrm{a}-\mathrm{c}$ & $21.43 \mathrm{bc}$ & $97.08 \mathrm{a}$ & $1.14 \mathrm{bc}$ & $17.67 \mathrm{~h}$ & $43.87 \mathrm{e}$ \\
\hline 4. $1 \mathrm{M}+1 \mathrm{~S} 15 \mathrm{~cm} \times 2.5 \mathrm{~cm}$ & $244.84 \mathrm{a}-\mathrm{c}$ & $20.30 \mathrm{de}$ & $93.34 \mathrm{ab}$ & $1.04 \mathrm{de}$ & $19.18 \mathrm{c}-\mathrm{f}$ & $45.13 \mathrm{a}-\mathrm{d}$ \\
\hline 5. $1 \mathrm{M}+1 \mathrm{~S} 15 \mathrm{~cm} \times 5.0 \mathrm{~cm}$ & $247.50 \mathrm{ab}$ & $20.79 \mathrm{~cd}$ & $94.96 \mathrm{ab}$ & $1.05 \mathrm{de}$ & $19.46 \mathrm{~b}-\mathrm{e}$ & $45.37 \mathrm{a}-\mathrm{c}$ \\
\hline $6.1 \mathrm{M}+1 \mathrm{~S} 10 \mathrm{~cm} \times 2.5 \mathrm{~cm}$ & 246.06 a-c & $20.13 \mathrm{de}$ & $94.84 \mathrm{ab}$ & $1.05 \mathrm{de}$ & $20.92 \mathrm{a}$ & 45.04 a-e \\
\hline 7. $1 \mathrm{M}+1 \mathrm{~S} 10 \mathrm{~cm} \times 5.0 \mathrm{~cm}$ & $240.66 \mathrm{bc}$ & $20.25 \mathrm{de}$ & $91.33 \mathrm{~b}$ & $1.24 \mathrm{a}$ & $20.08 \mathrm{a}-\mathrm{c}$ & $45.94 \mathrm{ab}$ \\
\hline 8. $2 \mathrm{M}+2 \mathrm{~S} 20 \mathrm{~cm} \times 2.5 \mathrm{~cm}$ & $248.78 \mathrm{a}$ & $21.92 \mathrm{ab}$ & $97.49 \mathrm{a}$ & $1.05 \mathrm{~cd}$ & $18.33 \mathrm{f}-\mathrm{h}$ & $44.78 \mathrm{~b}-\mathrm{e}$ \\
\hline 9. $2 \mathrm{M}+2 \mathrm{~S} 20 \mathrm{~cm} \times 5.0 \mathrm{~cm}$ & $244.08 \mathrm{a}-\mathrm{c}$ & $21.59 \mathrm{~b}$ & $94.90 \mathrm{ab}$ & $1.10 \mathrm{~cd}$ & $18.66 \mathrm{e}-\mathrm{g}$ & $43.96 \mathrm{de}$ \\
\hline $10.2 \mathrm{M}+2 \mathrm{~S} 15 \mathrm{~cm} \times 2.5 \mathrm{~cm}$ & $248.80 \mathrm{a}$ & 20.16 de & $95.86 \mathrm{ab}$ & $1.10 \mathrm{~cd}$ & $19.77 \mathrm{~b}-\mathrm{d}$ & $44.62 \mathrm{c}-\mathrm{e}$ \\
\hline $11.2 \mathrm{M}+2 \mathrm{~S} 15 \mathrm{~cm} \times 5.0 \mathrm{~cm}$ & $245.77 \mathrm{a}-\mathrm{c}$ & $20.38 \mathrm{de}$ & $97.03 \mathrm{a}$ & $1.03 \mathrm{e}$ & $19.03 \mathrm{~d}-\mathrm{f}$ & $43.90 \mathrm{e}$ \\
\hline $12.2 \mathrm{M}+2 \mathrm{~S} 10 \mathrm{~cm} \times 2.5 \mathrm{~cm}$ & $239.51 \mathrm{c}$ & $19.64 \mathrm{e}$ & $96.53 \mathrm{ab}$ & $1.06 \mathrm{de}$ & $20.37 \mathrm{ab}$ & $46.13 \mathrm{a}$ \\
\hline $13.2 \mathrm{M}+2 \mathrm{~S} 10 \mathrm{~cm} \times 5.0 \mathrm{~cm}$ & $245.13 \mathrm{a}-\mathrm{c}$ & $19.78 \mathrm{e}$ & $94.65 \mathrm{ab}$ & $1.17 \mathrm{ab}$ & $19.75 \mathrm{~b}-\mathrm{d}$ & $45.33 \mathrm{a}-\mathrm{c}$ \\
\hline E.G.F. $(\% 5)$ & 7.78 & 0.79 & 5.69 & 0.07 & 0.93 & 1.21 \\
\hline
\end{tabular}

BB:bitki boyu, BÇ:bitki çapı, İKY:ilk koçan yüksekliği, KS:koçan sayısı, KB:koçan boyu, KÇ:koçan çapı 
Çizelge 4. İkinci ürün tane mısırda birlikte yetiştirme uygulamaları ile koçan ağırlığı, bin tane ağırlığı, tepe püskülü çıkışına kadar geçen gün sayısı, olgunlaşma gün sayısı, tane verimi, ham protein verimine ait iki y1l ortalama değerleri ve oluşan gruplar

\begin{tabular}{lllllll}
\hline Uygulamalar & $\begin{array}{l}\text { KA } \\
(\mathrm{g})\end{array}$ & $\begin{array}{l}\text { BTA } \\
(\mathrm{g})\end{array}$ & $\begin{array}{l}\text { TPÇS } \\
(\mathrm{gün})\end{array}$ & $\begin{array}{l}\text { OGS } \\
(\mathrm{gün})\end{array}$ & $\begin{array}{l}\text { TV } \\
(\mathrm{kg} / \mathrm{da})\end{array}$ & $\begin{array}{l}\mathrm{HPV} \\
(\mathrm{kg} / \mathrm{da})\end{array}$ \\
\hline $1 . \mathrm{Saf}$ M1sir $70 \mathrm{~cm} \times 20 \mathrm{~cm}$ & $212.49 \mathrm{c}$ & $368.26 \mathrm{a}$ & $55.75 \mathrm{f}$ & $106.50 \mathrm{fg}$ & $663.17 \mathrm{bc}$ & $76.23 \mathrm{ab}$ \\
$2.1 \mathrm{M}+1 \mathrm{~S} 20 \mathrm{~cm} \times 2.5 \mathrm{~cm}$ & $251.63 \mathrm{a}$ & $332.03 \mathrm{~cd}$ & $57.38 \mathrm{e}$ & $106.50 \mathrm{fg}$ & $664.06 \mathrm{bc}$ & $77.26 \mathrm{ab}$ \\
$3.1 \mathrm{M}+1 \mathrm{~S} 20 \mathrm{~cm} \times 5.0 \mathrm{~cm}$ & $262.13 \mathrm{a}$ & $353.58 \mathrm{~b}$ & $57.50 \mathrm{e}$ & $106.38 \mathrm{~g}$ & $730.13 \mathrm{a}$ & $81.81 \mathrm{a}$ \\
$4.1 \mathrm{M}+1 \mathrm{~S} 15 \mathrm{~cm} \times 2.5 \mathrm{~cm}$ & $166.60 \mathrm{~d}$ & $331.03 \mathrm{~cd}$ & $57.38 \mathrm{e}$ & $106.63 \mathrm{fg}$ & $681.25 \mathrm{~b}$ & $61.77 \mathrm{~d}$ \\
$5.1 \mathrm{M}+1 \mathrm{~S} 15 \mathrm{~cm} \times 5.0 \mathrm{~cm}$ & $170.19 \mathrm{~d}$ & $315.12 \mathrm{e}$ & $57.25 \mathrm{e}$ & $106.50 \mathrm{fg}$ & $628.12 \mathrm{~cd}$ & $51.59 \mathrm{fg}$ \\
$6.1 \mathrm{M}+1 \mathrm{~S} 10 \mathrm{~cm} 2.5 \mathrm{~cm}$ & $99.55 \mathrm{f}$ & $328.12 \mathrm{de}$ & $57.88 \mathrm{~d}$ & $107.63 \mathrm{ab}$ & $563.17 \mathrm{e}$ & $54.25 \mathrm{e}-\mathrm{g}$ \\
$7.1 \mathrm{M}+1 \mathrm{~S} 10 \mathrm{~cm} \times 5.0 \mathrm{~cm}$ & $101.50 \mathrm{f}$ & $336.63 \mathrm{~cd}$ & $59.13 \mathrm{~b}-\mathrm{d}$ & $107.75 \mathrm{a}$ & $535.71 \mathrm{ef}$ & $61.12 \mathrm{~d}$ \\
$8.2 \mathrm{M}+2 \mathrm{~S} 20 \mathrm{~cm} \times 2.5 \mathrm{~cm}$ & $228.03 \mathrm{~b}$ & $341.08 \mathrm{~b}-\mathrm{d}$ & $58.00 \mathrm{~cd}$ & $106.50 \mathrm{fg}$ & $630.58 \mathrm{~cd}$ & $72.66 \mathrm{bc}$ \\
$9.2 \mathrm{M}+2 \mathrm{~S} 20 \mathrm{~cm} \times 5.0 \mathrm{~cm}$ & $225.50 \mathrm{bc}$ & $341.95 \mathrm{bc}$ & $59.00 \mathrm{~cd}$ & $106.50 \mathrm{fg}$ & $636.83 \mathrm{~cd}$ & $61.81 \mathrm{~d}$ \\
$10.2 \mathrm{M}+2 \mathrm{~S} 15 \mathrm{~cm} \times 2.5 \mathrm{~cm}$ & $166.74 \mathrm{~d}$ & $332.27 \mathrm{~cd}$ & $58.13 \mathrm{~b}-\mathrm{d}$ & $106.75 \mathrm{ef}$ & $642.19 \mathrm{~cd}$ & $68.21 \mathrm{c}$ \\
$11.2 \mathrm{M}+2 \mathrm{~S} 15 \mathrm{~cm} \times 5.0 \mathrm{~cm}$ & $147.76 \mathrm{e}$ & $332.32 \mathrm{~cd}$ & $58.25 \mathrm{a}-\mathrm{c}$ & $107.00 \mathrm{de}$ & $612.50 \mathrm{~d}$ & $48.72 \mathrm{~g}$ \\
$12.2 \mathrm{M}+2 \mathrm{~S} 10 \mathrm{~cm} \times 2.5 \mathrm{~cm}$ & $96.09 \mathrm{f}$ & $337.63 \mathrm{~cd}$ & $58.40 \mathrm{ab}$ & $107.38 \mathrm{be}$ & $521.87 \mathrm{f}$ & $54.92 \mathrm{ef}$ \\
$13.2 \mathrm{M}+2 \mathrm{~S} 10 \mathrm{~cm} \times 5.0 \mathrm{~cm}$ & $97.59 \mathrm{f}$ & $333.35 \mathrm{~cd}$ & $58.50 \mathrm{a}$ & $107.25 \mathrm{~cd}$ & $536.38 \mathrm{ef}$ & $57.90 \mathrm{de}$ \\
E.G.F. $(\% 5)$ & 14.77 & 13.64 & 0.34 & 0.28 & 37.64 & 5.85
\end{tabular}

KA:koçan ağırlığı, BTA:bin tane ağırlığı, TPÇS:tepe püskülü çıkış süresi, OGS:olgunlaşma gün sayısı, TV:tane verimi, HPV:ham protein verimi

Çizelge 5. İkinci ürün tane soyada birlikte yetiştirme uygulamaları ile bitki boyu, ilk bakla yüksekliği, dal sayısı, bakla sayısı, baklada tohum sayısı, bitki başına tane verimine ait iki yıl ortalama değerleri ve oluşan gruplar

\begin{tabular}{|c|c|c|c|c|c|c|}
\hline Uygulamalar & $\begin{array}{l}\mathrm{BB} \\
(\mathrm{cm})\end{array}$ & $\begin{array}{l}\mathrm{İBY} \\
(\mathrm{cm})\end{array}$ & $\begin{array}{l}\text { DS } \\
\text { (adet/bit.) }\end{array}$ & $\begin{array}{l}\text { BS } \\
\text { (adet/bit.) }\end{array}$ & $\begin{array}{l}\text { BTS } \\
\text { (adet/bit.) }\end{array}$ & $\begin{array}{l}\text { BBTV } \\
\text { (adet/bit.) }\end{array}$ \\
\hline 1.Saf Soya $35 \mathrm{~cm} \times 5.0 \mathrm{~cm}$ & $73.26 \mathrm{c}$ & $15.09 \mathrm{f}$ & $1.30 \mathrm{ab}$ & $31.01 \mathrm{a}$ & $2.40 \mathrm{a}$ & $11.43 \mathrm{a}$ \\
\hline 2. $1 \mathrm{M}+1 \mathrm{~S} 20 \mathrm{~cm} \times 2.5 \mathrm{~cm}$ & $71.83 \mathrm{c}$ & $18.14 \mathrm{a}-\mathrm{c}$ & $1.11 \mathrm{de}$ & $20.98 \mathrm{~d}$ & $2.19 \mathrm{~b}-\mathrm{e}$ & $7.78 \mathrm{~cd}$ \\
\hline 3. $1 \mathrm{M}+1 \mathrm{~S} 20 \mathrm{~cm} \times 5.0 \mathrm{~cm}$ & $74.49 \mathrm{a}-\mathrm{c}$ & $18.30 \mathrm{a}-\mathrm{c}$ & $1.18 \mathrm{~b}-\mathrm{d}$ & $22.94 \mathrm{c}-\mathrm{e}$ & $2.20 \mathrm{~b}-\mathrm{d}$ & $7.99 \mathrm{~cd}$ \\
\hline 4. $1 \mathrm{M}+1 \mathrm{~S} 15 \mathrm{~cm} \times 2.5 \mathrm{~cm}$ & $72.60 \mathrm{c}$ & $17.16 \mathrm{~b}-\mathrm{e}$ & $1.08 \mathrm{de}$ & $20.50 \mathrm{e}$ & $2.30 \mathrm{ab}$ & $7.77 \mathrm{~cd}$ \\
\hline 5. $1 \mathrm{M}+1 \mathrm{~S} 15 \mathrm{~cm} \times 5.0 \mathrm{~cm}$ & $73.10 \mathrm{c}$ & $16.90 \mathrm{c}-\mathrm{e}$ & $1.20 \mathrm{a}-\mathrm{d}$ & 20.76 e & $2.11 \mathrm{e}$ & $7.38 \mathrm{~d}$ \\
\hline $6.1 \mathrm{M}+1 \mathrm{~S} 10 \mathrm{~cm} \times 2.5 \mathrm{~cm}$ & $77.14 \mathrm{a}-\mathrm{c}$ & $20.58 \mathrm{a}$ & $1.05 \mathrm{e}$ & $22.94 \mathrm{c}-\mathrm{e}$ & $2.12 \mathrm{de}$ & $8.61 \mathrm{c}$ \\
\hline 7. $1 \mathrm{M}+1 \mathrm{~S} 10 \mathrm{~cm} \times 5.0 \mathrm{~cm}$ & 73.46 be & $15.88 \mathrm{c}-\mathrm{e}$ & $1.20 \mathrm{a}-\mathrm{d}$ & $24.90 \mathrm{c}$ & $2.21 \mathrm{~b}-\mathrm{e}$ & $7.42 \mathrm{~d}$ \\
\hline 8. $2 \mathrm{M}+2 \mathrm{~S} 20 \mathrm{~cm} \times 2.5 \mathrm{~cm}$ & $75.63 \mathrm{a}-\mathrm{c}$ & $17.85 \mathrm{~b}-\mathrm{d}$ & $1.11 \mathrm{de}$ & $23.16 \mathrm{c}-\mathrm{e}$ & 2.25 be & $7.97 \mathrm{~cd}$ \\
\hline 9. $2 \mathrm{M}+2 \mathrm{~S} 20 \mathrm{~cm} \times 5.0 \mathrm{~cm}$ & $79.59 \mathrm{ab}$ & $17.85 \mathrm{~b}-\mathrm{d}$ & $1.25 \mathrm{a}-\mathrm{c}$ & $24.93 \mathrm{c}$ & $2.17 \mathrm{c}-\mathrm{e}$ & $8.64 \mathrm{bc}$ \\
\hline $10.2 \mathrm{M}+2 \mathrm{~S} 15 \mathrm{~cm} \times 2.5 \mathrm{~cm}$ & $80.08 \mathrm{a}$ & $19.79 \mathrm{ab}$ & $1.16 \mathrm{c}-\mathrm{e}$ & $24.78 \mathrm{~cd}$ & $2.22 \mathrm{~b}-\mathrm{e}$ & $7.72 \mathrm{~cd}$ \\
\hline $11.2 \mathrm{M}+2 \mathrm{~S} 15 \mathrm{~cm} \times 5.0 \mathrm{~cm}$ & $75.97 \mathrm{a}-\mathrm{c}$ & $17.81 \mathrm{~b}-\mathrm{d}$ & $1.33 \mathrm{a}$ & $26.81 \mathrm{bc}$ & $2.27 \mathrm{bc}$ & $8.31 \mathrm{~cd}$ \\
\hline $12.2 \mathrm{M}+2 \mathrm{~S} 10 \mathrm{~cm} \times 2.5 \mathrm{~cm}$ & $75.89 \mathrm{a}-\mathrm{c}$ & $18.06 \mathrm{a}-\mathrm{d}$ & $1.19 \mathrm{~b}-\mathrm{d}$ & $25.98 \mathrm{bc}$ & $2.23 \mathrm{~b}-\mathrm{e}$ & $8.60 \mathrm{c}$ \\
\hline $13.2 \mathrm{M}+2 \mathrm{~S} 10 \mathrm{~cm} \times 5.0 \mathrm{~cm}$ & $74.15 \mathrm{a}-\mathrm{c}$ & $15.36 \mathrm{de}$ & $1.16 \mathrm{c}-\mathrm{e}$ & $29.68 \mathrm{ab}$ & $2.24 \mathrm{~b}-\mathrm{d}$ & $9.76 \mathrm{~b}$ \\
\hline E.G.F. (\%5) & 6.30 & 2.70 & 0.13 & 3.92 & 0.12 & 1.13 \\
\hline
\end{tabular}

BB:bitki boyu, İBY:ilk bakla yüksekliği, DS:dal sayısı, BS:bakla sayısı, BTS:baklada tohum sayıs1, BBTV:bitki başına tane verimi 
Çizelge 6. İkinci ürün tane soyada birlikte yetiştirme uygulamaları ile bin tane ağırlığı, tane verimi, çiçeklenme gün sayısı, olgunlaşma gün sayısı, ham protein verimi ait iki yıl ortalama değerleri ve oluşan gruplar

\begin{tabular}{llllll}
\hline Uygulamalar & $\begin{array}{l}\text { BTA } \\
(\mathrm{g})\end{array}$ & $\begin{array}{l}\text { TV } \\
(\mathrm{kg} / \mathrm{da})\end{array}$ & $\begin{array}{l}\text { \%50 ÇGS } \\
(\mathrm{gün})\end{array}$ & OGS (gün) & $\begin{array}{l}\text { HPV } \\
(\mathrm{kg} / \mathrm{da})\end{array}$ \\
\hline $1 . S a f$ Soya $35 \mathrm{~cm} \times 5.0 \mathrm{~cm}$ & $144.33 \mathrm{a}$ & $226.58 \mathrm{a}$ & $39.50 \mathrm{~h}$ & $114.50 \mathrm{~g}$ & $73.95 \mathrm{a}$ \\
$2.1 \mathrm{M}+1 \mathrm{~S} 20 \mathrm{~cm} \times 2.5 \mathrm{~cm}$ & $133.84 \mathrm{bc}$ & $64.98 \mathrm{c}-\mathrm{e}$ & $40.63 \mathrm{~g}$ & $115.00 \mathrm{f}$ & $20.18 \mathrm{~d}-\mathrm{f}$ \\
$3.1 \mathrm{M}+1 \mathrm{~S} 20 \mathrm{~cm} \times 5.0 \mathrm{~cm}$ & $125.85 \mathrm{ef}$ & $51.24 \mathrm{f}$ & $40.63 \mathrm{~g}$ & $115.38 \mathrm{ef}$ & $15.71 \mathrm{~g}$ \\
$4.1 \mathrm{M}+1 \mathrm{~S} 15 \mathrm{~cm} \times 2.5 \mathrm{~cm}$ & $122.11 \mathrm{f}$ & $63.20 \mathrm{e}$ & $41.25 \mathrm{f}$ & $116.00 \mathrm{~b}-\mathrm{d}$ & $19.43 \mathrm{ef}$ \\
$5.1 \mathrm{M}+1 \mathrm{~S} 15 \mathrm{~cm} \times 5.0 \mathrm{~cm}$ & $126.85 \mathrm{~d}-\mathrm{f}$ & $60.98 \mathrm{e}$ & $41.50 \mathrm{ef}$ & $116.25 \mathrm{a}-\mathrm{c}$ & $19.71 \mathrm{ef}$ \\
$6.1 \mathrm{M}+1 \mathrm{~S} 10 \mathrm{~cm} \times 2.5 \mathrm{~cm}$ & $137.28 \mathrm{~b}$ & $68.36 \mathrm{~b}-\mathrm{e}$ & $41.3: 3 \mathrm{f}$ & $116.63 \mathrm{a}$ & $22.52 \mathrm{~b}-\mathrm{d}$ \\
$7.1 \mathrm{M}+1 \mathrm{~S} 10 \mathrm{~cm} \times 5.0 \mathrm{~cm}$ & $132.98 \mathrm{bc}$ & $66.79 \mathrm{c}-\mathrm{e}$ & $41.3: 3 \mathrm{f}$ & $115.75 \mathrm{de}$ & $20.56 \mathrm{~d}-\mathrm{f}$ \\
$8.2 \mathrm{M}+2 \mathrm{~S} 20 \mathrm{~cm} \times 2.5 \mathrm{~cm}$ & $126.70 \mathrm{~d}-\mathrm{f}$ & $62.03 \mathrm{e}$ & $42.13 \mathrm{bc}$ & $115.88 \mathrm{~cd}$ & $18.71 \mathrm{f}$ \\
$9.2 \mathrm{M}+2 \mathrm{~S} 20 \mathrm{~cm} \times 5.0 \mathrm{~cm}$ & $131.25 \mathrm{~b}-\mathrm{e}$ & $66.18 \mathrm{c}-\mathrm{e}$ & $41.8: 3 \mathrm{~cd}$ & $116.00 \mathrm{~b}-\mathrm{d}$ & $20.88 \mathrm{c}-\mathrm{f}$ \\
$10.2 \mathrm{M}+2 \mathrm{~S} 15 \mathrm{~cm} \times 2.5 \mathrm{~cm}$ & $130.63 \mathrm{c}-\mathrm{e}$ & $73.35 \mathrm{bc}$ & $42.25 \mathrm{ab}$ & $116.63 \mathrm{a}$ & $23.14 \mathrm{be}$ \\
$11.2 \mathrm{M}+2 \mathrm{~S} 15 \mathrm{~cm} \times 5.0 \mathrm{~cm}$ & $133.05 \mathrm{bc}$ & $63.66 \mathrm{de}$ & $41.83 \mathrm{~cd}$ & $116.25 \mathrm{a}-\mathrm{c}$ & $19.76 \mathrm{ef}$ \\
$12.2 \mathrm{M}+2 \mathrm{~S} 10 \mathrm{~cm} \times 2.5 \mathrm{~cm}$ & $135.10 \mathrm{bc}$ & $72.55 \mathrm{~b}-\mathrm{d}$ & $42.50 \mathrm{a}$ & $116.39 \mathrm{ab}$ & $21.51 \mathrm{~b}-\mathrm{e}$ \\
$13.2 \mathrm{M}+2 \mathrm{~S} 10 \mathrm{~cm} \times 5.0 \mathrm{~cm}$ & $132.10 \mathrm{~b}-\mathrm{d}$ & $75.92 \mathrm{~b}$ & $41.75 \mathrm{de}$ & $115.75 \mathrm{de}$ & $23.49 \mathrm{~b}$ \\
E.G.F. $(\% 5)$ & 6.07 & 9.05 & 0.37 & 0.40 & 2.47 \\
\hline
\end{tabular}

BTA: bin tane ağırlı̆̆ı, TV: tane verimi, \%50 ÇGS: çiçeklenme gün sayısı, OGS: olgunlaşma gün sayısı, HPV: ham protein verimi

Çizelge 7. Saf ve birlikte yetiştirilen ikinci ürün mısırda iki yıl birleştirilmiş verilerin karakterler arası ilişkileri

\begin{tabular}{|c|c|c|c|c|c|c|c|c|c|c|c|}
\hline Karakterler & $\mathrm{BC}$ & $\overline{\mathrm{I}} \mathrm{IKY}$ & $\mathrm{KS}$ & $\mathrm{KBB}$ & KÇ & KA & BTA & TPÇS & OGS & TV & HPV \\
\hline $\mathrm{BB}(\mathrm{cm})$ & 0.100 & $0.519 * *$ & -0.093 & -0.275 & -0.182 & 0.184 & 0.009 & $-0.531 * *$ & $-0.621 * *$ & -0.010 & $0.317 *$ \\
\hline $\mathrm{BÇ}(\mathrm{mm})$ & & 0.075 & -0.111 & -0.288 & 0.209 & $0.612 * *$ & $0.296^{*}$ & -0.275 & -0.127 & $0.306^{*}$ & $0.376^{*}$ \\
\hline İKY (cm) & & & -0.015 & -0.222 & -0.160 & 0.214 & -0.037 & -0.289 & -0.278 & 0.102 & 0.256 \\
\hline KS (adet/bit.) & & & & 0.090 & 0.068 & -0.162 & 0.134 & 0.145 & 0.095 & -0.111 & 0.120 \\
\hline $\mathrm{KB}(\mathrm{cm})$ & & & & & $0.570 * *$ & $-0.491 * *$ & -0.073 & $0.457 * *$ & $0.565 * *$ & -0.233 & $-0.451 * *$ \\
\hline $\mathrm{KÇ}(\mathrm{mm})$ & & & & & & $-0.336^{*}$ & -0.115 & $0.341 *$ & $0.404 * *$ & -0.180 & -0.260 \\
\hline $\mathrm{KA}(\mathrm{g})$ & & & & & & & $0.319 *$ & -0.214 & -0.230 & $0.667 * *$ & $0.539 * *$ \\
\hline BTA (g) & & & & & & & & -0.090 & -0.012 & 0.179 & $0.301^{*}$ \\
\hline TPÇ (gün) & & & & & & & & & $0.850 * *$ & 0.002 & $-0.456^{* * *}$ \\
\hline OGS (gün) & & & & & & & & & & 0.094 & $-0.419 * *$ \\
\hline TV (kg/da) & & & & & & & & & & & $0.515^{* *}$ \\
\hline
\end{tabular}

BB: bitki boyu, BÇ: bitki çapı, İKY: ilk koçan yüksekliği, KS: koçan sayısı, KB: koçan boyu, KÇ: koçan çapı, KA: koçan ağırlığı, BTA: bin tane ağırlığı, TPÇS: tepe püskülü çıkış süresi, OGS: olgunlaşma gün sayısı, TV: bitki tane verimi, HPV: ham protein verimi

İkinci ürün mısırda karakterler arası ilişkileri belirlemek için hesaplanan korelasyon katsayıları Çizelge 7'den bitki boyu ile ilk koçan yüksekliği ve ham protein verimi arasında önemli ve olumlu, tepe püskülü çıkışı ve olgunlaşma gün sayısıarasında ise önemli ve olumsuz ilişki görülmektedir. Bitki çapı ile koçan ağırlığı, bin tane ağırlığı, tane verimi ve ham protein verimi arasında önemli, ve olumlu, koçan boyu ile koçan çap1, tepe püskülü çıkışı ve olgunlaşma gün sayısı arasında önemli ve olumlu ilişki varken, koçan ağırlığı ve ham protein verimi arasında önemli ve olumsuz, koçan çapı ile tepe püskülü çıkışı ve olgunlaşma gün sayısı karakterleri arasında önemli ve olumlu, aynı karakterin koçan ağırlığı arasında ise önemli ve olumsuz ilişki saptanmıştır. Koçan ağırlığı ile bin tane ağırlığı, tane verimi ve ham protein 
verimi arasında, bin tane ağırlığı ile ham protein verimi arasında, tepe püskülü çıkışına kadar geçen gün sayısı ile olgunlaşma gün sayısı ve ham protein verimi arasında, tane verimi ile ham protein verimi arasında önemli ve olumlu ilişkiler görülebilir (Çizelge 7). Ayrıca Olgunlaşma gün sayısı ile ham protein verimi arasında önemli ve olumsuz ilişki saptanmıştır. Elde edilen bulgular bin tane ağırlı̆̆ ile dane verimi arasında pozitif ilişkiler saptayan Adesoji ve ark. (2015)'ın bulgularıyla benzerlik göstermektedir.

Çizelge 8. Saf ve birlikte yetiştirilen soyada iki yıl birleştirilmiş verilerin karakterler arası ilişkileri

\begin{tabular}{|c|c|c|c|c|c|c|c|c|c|c|}
\hline Karakterler & İBY & DS & BS & BTS & BBTV & NTA & TV & \%50 ÇGS & OGS & HPV \\
\hline $\mathrm{BB}(\mathrm{cm})$ & $0.423^{* *}$ & -0.248 & $0.352 *$ & 0.191 & $-0.440 * *$ & $-0.318^{*}$ & -0.091 & $0.341 *$ & -0.061 & -0.043 \\
\hline İBY $(\mathrm{cm})$ & & $-0.320^{*}$ & $-0.385 * *$ & -0.138 & -0.215 & -0.101 & -0.206 & 0.178 & $0.332 *$ & -0.212 \\
\hline DS (adet/bitki) & & & $0.703 * *$ & $0.385^{* *}$ & -0.134 & -0.100 & 0.159 & 0.044 & -0.248 & 0.194 \\
\hline BS (adet/bitki) & & & & $0.383 * *$ & -0.096 & -0.119 & 0.212 & 0.043 & $-0.332 *$ & 0.265 \\
\hline BTS(adet/bitki) & & & & & -0.068 & -0.074 & $-0.316^{*}$ & -0.040 & $-0.325^{*}$ & $0.345^{*}$ \\
\hline BBTV(adet/bitki) & & & & & & $0.557^{* * *}$ & $0.491 * *$ & $-0.355^{*}$ & 0.062 & $0.451 * *$ \\
\hline BTA (g) & & & & & & & $0.381 * *$ & -0.247 & 0.031 & $0.325^{*}$ \\
\hline $\mathrm{TV}(\mathrm{kg} / \mathrm{da})$ & & & & & & & & $-0.563 * *$ & $-0.384 * *$ & $0.987^{* *}$ \\
\hline \%50 ÇGS (gün) & & & & & & & & & $0.482 * *$ & $-0.565^{* *}$ \\
\hline OGS (gün) & & & & & & & & & & $-0.401 * *$ \\
\hline
\end{tabular}

$*: \mathrm{p} \leq 0.05$ seviyesinde, $* *: \mathrm{p}<0.01$ seviyesinde önemlidir

BB: bitki boyu, İBY: ilk bakla yüksekliği, DS: dal sayısı, BS: bakla sayısı, BTS: baklada tohum sayısı, BBTV: bitki başına tohum verimi, BTA: bin tane ağırlığı, TV: tane verimi, \%50 ÇGS: çiçeklenme gün sayısı, OGS: olgunlaşma gün sayıs1, HPV: ham protein verimi

Çizelge 8'den izlendiği gibi bitki boyu ile bakla sayısı, \%50 çiçeklenme gün sayısı ve ilk bakla yüksekliği arasında, dal sayısı ile bakla sayısı ve baklada tohum sayısı arasında önemli ve olumlu, baklada tohum sayısının ham protein verimi arasında, bitki başına tohum veriminin bin tane ağırlığ protein verimi arasında önemli ve olumlu, tane verimiyle ham protein verimi arasında önemli ve olumlu, aynı karakter ile \%50 çiçeklenme gün sayısı ve olgunlaşma gün sayısı arasında ise önemli ve olumsuz ilişkiden söz edebiliriz.

Olgunlaşma gün sayısı arasında ile ham protein verimi arasında önemli ve olumsuz ilişki saptanmıştır. Soyada tane verimi ve bin tane ağırlığı arasında önemli ve pozitif koralasyon gözlemlemiş olan Boroomandan ve ark., (2009) ile bulgularımız uyumludur.

Elde edilen bulgulara göre; birlikte yetiştirme sistemi çalışmalarında bitki boyu, ilk koçan yüksekliği, dal sayısı, bakla sayısı, baklada tohum sayısının karakterlerinin dikkate alınması verim ve kalite açısından önemli olabileceğini söylemek mümkündür.

Ekler

Bu çalışma, (Tez No: 25293) Doktora tezimden hazırlanmıştır.

\section{KAYNAKLAR}

Adesoji AG, Abubakar IU and Labe DA 2015. Character association and path coefficient analysis of maize (Zea mays L.) grown under incorporated legumes and nitrogen. Journal of Agronomy 14 (3): $158-163$

Anonim, 1991. Adana İline ait 1990-91 ve uzun yıllar iklim verileri. Adana Meteoroloji İl Müdürlüğü

Bilgen, M.,Tansı, V., Sağlamtimur, T. 1991. Antalya ovası koşullarında mısırın üç değişik baklagil ile birlikte yetiştirilme olanakları üzerinde araştırmalar. Türkiye 2.Çayır Mera ve Yembitkileri Kongresi, 28-31 Mayıs, İzmir, s.379-388.

Boroomandan, P.M., Khoramivafa, M., Haghi, Y., Ebrahimi, A. 2009. The effects of nitrogen starter fertilizer and plant density on yield, yield components and oil and protein content of soybean (Glycine max L. Merr). Pakistan Journal of Biological Sciences, (12), p: 378-382 
Boz, A.R. 2006. Çukurova koşullarında ayçiçeği (Helianthus annuus L.) ve börülce (Vigna sinensis L.)' nin hasıl olarak birlikte yetiştirilme olanaklarının saptanması üzerine bir araştırma. ÇÜ., Fen Bilimleri Enstitüsü, Doktora Tezi, 111s.

Bryon, W. B., Peprah, S. A., 1988. Effect of planting sequence and time, and nitrogen on maize legume intercrop yield. Journal Agron.\&Crop Science. 161:17-22.

Eser D., 1986. Tarımsal ekoloji. Ankara üniversitesi ziraat fak. Yayınları, No:287. Ankara Üniversitesi Basımevi, Ankara. 176s.

Gençtan T., Emeklier Y., Çölkesen M ve Başer İ., 1995. Sıcak İklim Tahılların Tüketim Projeksiyonları ve Üretim Hedefleri. Türkiye Ziraat Mühendisliği IV. Teknik Kongresi, Ziraat Mühendisleri Odası, 9-13 Ocak, Ankara, 1: s.429-448.

Kolsarıcı Ö., Gür A., Başalma D., Kaya M.D ve İşler N., 2004. Yağlı Tohumlu Bitkiler Üretimi. VI. Türkiye Ziraat Mühendisliği Teknik Kongresi, 3-7 Ocak, Ankara, (1): s.21

Özbek, H., Dinç, U., Kapur, S. A., 1974. Ç. Ü. Yerleşim sahası topraklarının detaylı etüd ve haritası. Ç.Ü. Ziraat Fakültesi yayınları; 73, Bilimsel araştırmalar ve incelemeler; A.Ü.basımevi 8, 149s.

Putnam, D.H., Herbert, S.J. and Vargas, A. 1985. Intercropped corn-soybean density studies. I. yield complementarity. Exp. Agric., 21: 41-45.

Shah, M. H., Koul, P. K., Khanday, B. A., Kachroo, D., 1991 Production potential and monetary adventage index or maize intercropped with different grain legumes. Indian Journal or Agronomy 36(1):23-28.

Singh, B., Awasthi, O.P., 1984. Intercropping with legume and oil-seed crops in maize at different spacings under rainfed conditions. Field Crop Abstracts37(6): 415. No: 3807.

Tansı, V., 1987, Çukurova bölgesinde mısır ve soyanın ikinci ürün olarak değişik ekim sistemlerinden birlikte yetiştirmenin tane ve hasıl verimine etkisi üzerine araştırmalar, Doktora tezi, $C$. $\ddot{U}$., Fen Bil. Enst., 241s. 